\title{
GEOMETRIC AND RADIOMETRIC EVALUATION OF RASAT IMAGES
}

\author{
Ali Cam ${ }^{\text {* }}$, Hüseyin Topan ${ }^{\text {a }}$, Murat Oruç ${ }^{\text {a }}$, Mustafa Özendi a , Çağlar Bayık ${ }^{\text {a }}$ \\ a BEU, Engineering Faculty, Department of Geomatics Engineering, 67100, Zonguldak, Turkey - (alicam193@ gmail.com, \\ topan@beun.edu.tr, orucm@hotmail.com, mustafa.ozendi@beun.edu.tr, caglarbayik@beun.edu.tr)
}

\section{Commission I, WG I/4}

KEY WORDS: RASAT, Georeferencing Accuracy, Radiometric Quality, Effective GSD, SNR Analysis.

\begin{abstract}
:
RASAT, the second remote sensing satellite of Turkey, was designed and assembled, and also is being operated by TÜBITAK Uzay (Space) Technologies Research Institute (Ankara). RASAT images in various levels are available free-of-charge via Gezgin portal for Turkish citizens. In this paper, the images in panchromatic (7.5 m GSD) and RGB (15 m GSD) bands in various levels were investigated with respect to its geometric and radiometric characteristics. The first geometric analysis is the estimation of the effective GSD as less than 1 pixel for radiometrically processed level (L1R) of both panchromatic and RGB images. Secondly, 2D georeferencing accuracy is estimated by various non-physical transformation models (similarity, 2D affine, polynomial, affine projection, projective, DLT and GCP based RFM) reaching sub-pixel accuracy using minimum 39 and maximum 52 GCPs. The radiometric characteristics are also investigated for 8 bits, estimating SNR between 21.8-42.2, and noise 0.0-3.5 for panchromatic and MS images for L1R when the sea is masked to obtain the results for land areas. The analysis show that RASAT images satisfies requirements for various applications. The research is carried out in Zonguldak test site which is mountainous and partly covered by dense forest and urban areas.
\end{abstract}

\section{INTRODUCTION}

\subsection{RASAT Mission}

Following the first experience with Bilsat mission, RASAT is the second remote sensing satellite of Turkey, launched in August 17, 2011. RASAT was designed and assembled with national experience in TÜBİTAK (The Scientific and Technological Research Council of Turkey) Space (Uzay) Technologies Research Institute, funded by Ministry of Development. The specifications of RASAT can be listed in Table 1 (Çinar, 2014).

\begin{tabular}{|l|l|}
\hline Orbit type & Sun-synchronised \\
Orbital inclination & $98.1^{\circ}$ \\
Orbital height & $\sim 700 \mathrm{~km}$ \\
Orbital period & $98.8 \mathrm{~min}$ \\
Local time ascending node & 10.30 (local time) \\
Mass & $93 \mathrm{~kg}$ \\
GSD in panchromatic band & $7.5 \mathrm{~m}$ \\
GSD in VNIR bands & $15 \mathrm{~m}$ \\
Radiometric resolution & $8 \mathrm{bit}$ \\
Temporal resolution & 2.5 days \\
Spectral resolution & Pan: $0.42-0.73 \mu \mathrm{m}$ \\
& Red: $0.58-0.73 \mu \mathrm{m}$ \\
& Green: $0.55-0.58 \mu \mathrm{m}$ \\
& Blue: $0.42-0.55 \mu \mathrm{m}$ \\
\hline
\end{tabular}

Table 1. Specifications of RASAT.

Comparing with the previous non-operational satellite, Bilsat, RASAT has higher radiometric and geometric resolution. Nevertheless, GÖKTÜRK-2 has higher resolution in all resolutions except temporal one.

\subsection{Existing Studies}

The existing studies related to the radiometric and geometric evaluation are presented by Türkmenoğlu and Yağlığlu (2013) mentioned the on-orbit Modulation Transfer Function of RASAT images. The image processing workflow was introduced by Teke (2016). Küpçü et al. (2014) and Erdogan et al. (2016) investigated the georeferencing accuracy of RASAT images.

\subsection{Aim and Organisation of the Paper}

This study is focused on the investigation of geometric and radiometric evaluation of RASAT images in various levels, covering Zonguldak test site (Turkey). At first, the results of analysis w.r.t. the noise, Signal to Noise Ratio (SNR) and effective Ground Sampling Distance (GSD) are presented. Then, the relative and absolute georeferencing accuracies in 2 dimension are presented for various image levels.

\section{ANALYSIS}

\subsection{Radiometric Evaluation}

RASAT images are distributed in various product levels. The investigated images are available in the following levels (Teke, 2016):

- Level 1: Radiometric correction applied,

- Level 1R: Band registration completed,

- Level 2: Georeferenced,

- Level 3: Orthorectified using DEM.

Figure 1 shows the Level 1R images in panchromatic and RGB (Red Green Blue) bands.

Since Level 1 is the closest one to the original one version in terms of radiometric characteristics, the radiometric evaluation was carried out only for this level. Figure 2 shows the histograms of all bands. The images are acquired in 8 bits (256 grey values), and the histograms covers most part of grey scale (Figure 2).

\footnotetext{
* Corresponding author
} 

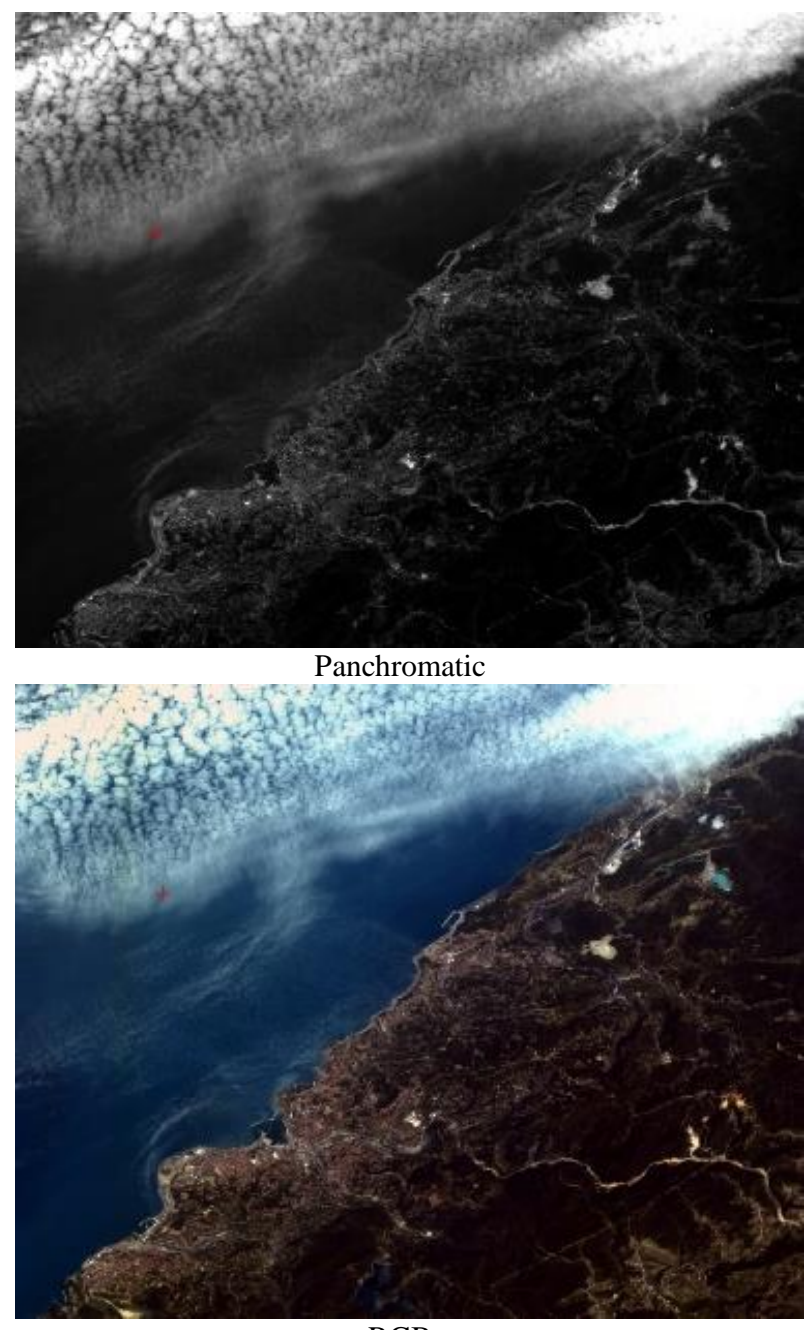

RGB

Figure 1. Images investigated in Level 1R.

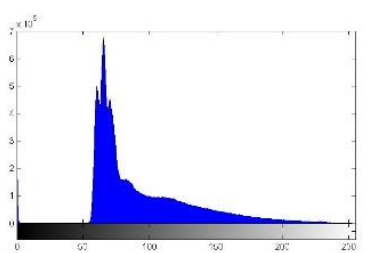

Panchromatic

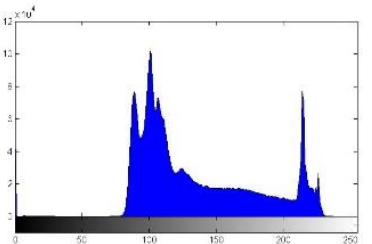

Green

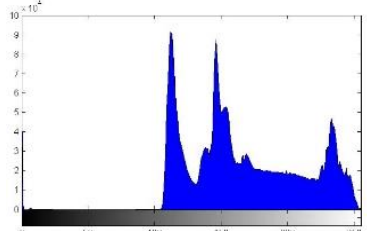

Blue

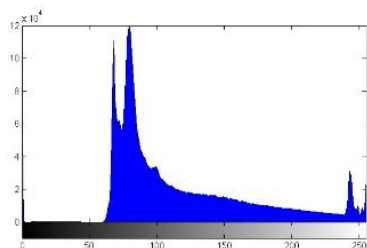

Red
Figure 2. Image histograms for Level 1.

Image noise and Signal to Noise Ratio (SNR) were estimated grouping grey values $(0-510)$ into five bins. This grouping is necessary, because the detectors may have different response in various intensities, and also the calculation is based on the number of pixels. Figure 3 illustrates the noise and SNR values. The noise is the standard deviation of the grey values in relation to the average grey value in the selected sub-area. On the other hand, SNR is the relation of the weighted noise average and the average grey value. It can be concluded that noise is systematically rising in panchromatic band, while this is not observed in other bands. The noise is almost equal in all bins both for green and blue bands. Although the SNR is almost equal in green and blue bands, it is smaller in panchromatic and red bands.

The nominal and effective GSD may be different because of Edge Spread Function. So the effective GSD must be estimated using edges (such as roof boundaries etc.) both with contrast and texture. The edges must have various directions to overcome the imaging-direction effect. The effective GSD of both panchromatic and RGB images were estimated about 1 pixel. This means the images are used by their original GSD values.

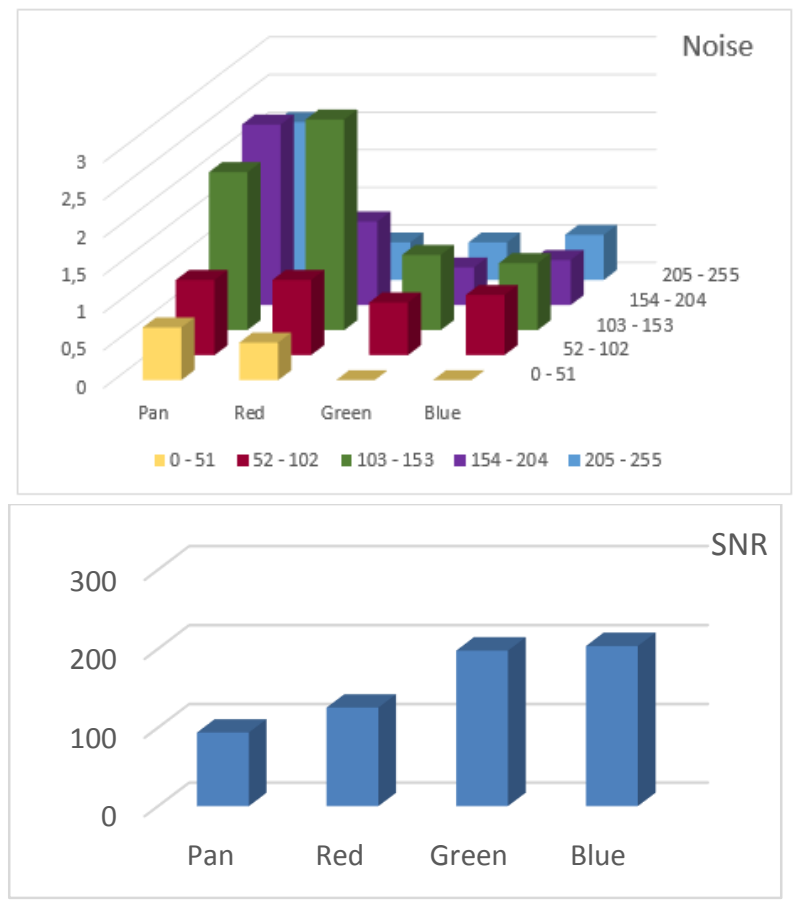

Figure 3. Noise and SNR for Level 1.

\subsection{Geometric Evaluation}

Since the stereo images were not available, the geometric evaluation was carried out by the georeferencing accuracy assessment in the image domain. Level 1R (L1R), Level 1RB (L1RB), Level 2 (L2) and Level 3 (L3) images were investigated. The GCPs were distributed both in horizontal and vertical directions (Figure 4). Because of radiometric differences, different number of GCPs selected on different levels. Besides, the object identification is very poor on the forest areas.

The sensor orientation parameters or Rational Polynomial Coefficients (RPCs) were not available. Because of this fact, the georeferencing accuracy assessment was carried out by various sensor-independent transformation models. Affine projection, Direct Linear Transformation (DLT) and GCP based RFM project $3 \mathrm{D}$ object space into $2 \mathrm{D}$ image space. Using Least Squares Estimation, the circular misfits $\left(m_{0}= \pm \sqrt{m_{x}^{2}+m_{y}^{2}}\right)$ at GCPs' image coordinates were estimated as listed in Table 3. Projective, DLT and RFM are the nonlinear iterative transformations. 

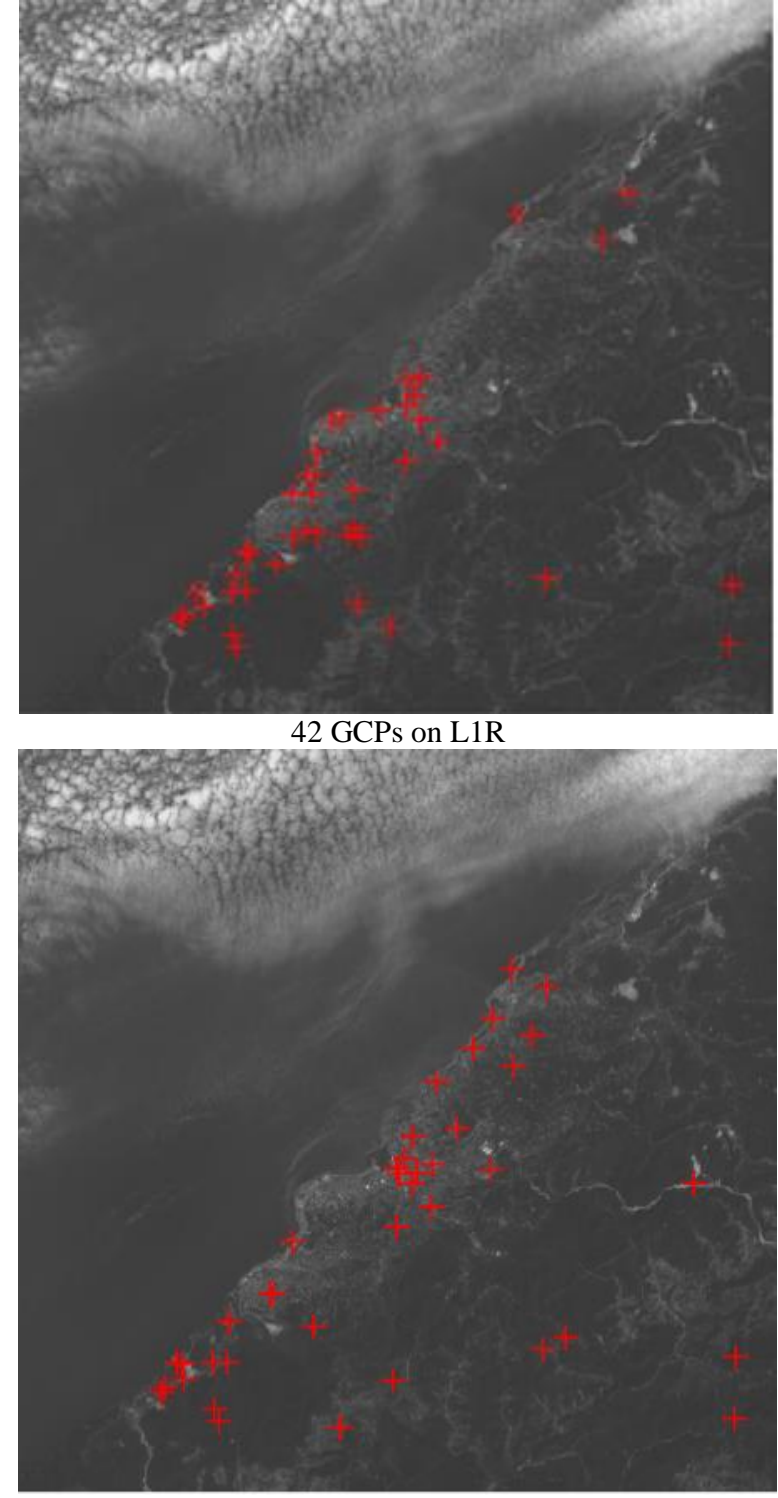

39 GCPs on L1RB

Figure 4. Sample GCP distribution.

As expected, the similarity transformation resulted the worst accuracy. The result for L2 and L3 is extremely better than others because these images are the products which was corrected using GCPs by the vendor. The polynomial transformation with higher order did not improve the results. The performance of affine projections may be important because this linear transformation can model the distortion based on terrain height. This transformation has three versions (Topan and Kutoglu, 2009). The Model 2 adapted for OrbView- 3 achieved the best among all models. All models of affine projection resulted in equal results. Projective and DLT might be compared. The accuracy was a little bit increased by DLT because DLT reflects the terrain height. Finally speaking, $1^{\text {st }}$ order RFM is enough for better accuracy since others have possible correlation among them. The best accuracy was $\sim$ half pixel by the L3 product which is an orthoimage generated by the vendor.

The error vectors were also analysed. The systematic effect is available in similarity transformation, as a result of this model's nature. Other methods have non-systematic vectors ignoring the local ones as expected. Figure 5 presents the comparison of error vectors generated for $1^{\text {st }}$ order RFM.

\begin{tabular}{|c|c|c|c|c|c|}
\hline \multirow{2}{*}{\multicolumn{2}{|c|}{ Methods }} & \multicolumn{4}{|c|}{ Level } \\
\hline & & L1R & L1RB & L2 & L3 \\
\hline \multicolumn{2}{|l|}{ \# GCP } & 42 & 39 & 52 & 39 \\
\hline \multicolumn{2}{|c|}{ Similarity } & 25.27 & 36.10 & 2.58 & 1.83 \\
\hline \multicolumn{2}{|l|}{ Affine } & 1.15 & 0.79 & 0.91 & 0.54 \\
\hline \multirow{5}{*}{ 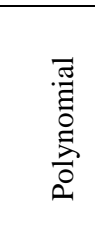 } & $1^{0}$ & 1.15 & 0.79 & 0.91 & 0.54 \\
\hline & $2^{0}$ & 1.05 & 0.79 & 0.92 & 0.55 \\
\hline & $3^{0}$ & 1.01 & 0.80 & 0.89 & 0.52 \\
\hline & $4^{0}$ & 0.93 & 0.84 & 0.88 & 0.54 \\
\hline & $5^{0}$ & 0.93 & 0.87 & 0.83 & 0.55 \\
\hline \multirow{3}{*}{ 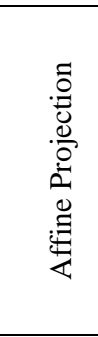 } & $\begin{array}{l}\text { Model } 1 \\
\text { (General) }\end{array}$ & 1.12 & 0.79 & 0.88 & 0.52 \\
\hline & $\begin{array}{l}\text { Model } 2 \\
\text { (OrbView- } \\
\text { 3) }\end{array}$ & 1.04 & 0.80 & 0.87 & 0.54 \\
\hline & $\begin{array}{l}\text { Model } 3 \\
\text { (IKONOS } \\
\& \\
\text { QuickBird) }\end{array}$ & 1.03 & 0.79 & 0.86 & 0.54 \\
\hline \multicolumn{2}{|c|}{ Projective } & 1.14 & 0.78 & 0.91 & 0.54 \\
\hline \multicolumn{2}{|l|}{ DLT } & 1.10 & 0.78 & 0.87 & 0.52 \\
\hline \multirow{3}{*}{ 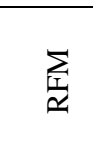 } & $1^{0}$ & 1.06 & 0.79 & 0.87 & 0.53 \\
\hline & $2^{0}$ & 16.72 & 3.55 & 3.56 & 0.14 \\
\hline & $3^{0}$ & 0.40 & NA & 1.23 & NA \\
\hline
\end{tabular}

Table 3. Georeferencing accuracy in image domain ( \pm pixel)

\section{CONCLUSION}

RASAT is the second remote sensing satellite of Turkey. Its panchromatic and RGB images in various levels were investigated with respect to geometric and geometric evaluation in this study.

The radiometric evaluation for panchromatic band shows us that the noise is higher for the bins that have higher grey values. The SNR values were almost similar in green and blue bands, and were smaller in panchromatic and red bands.

The georeferencing accuracy was estimated in image domain because the stereo images were not available. The sensorindependent models were used due to the absence of the parameters of sensor orientation model or RPCs. The circular error is about \pm 1 pixel in the image levels with original geometry, and is \pm 0.52 pixels in the orthoimage produced by the vendor.

Although the radiometric and geometric resolution of RASAT is limited, the images will be improved the experience with its freeof-charge distribution policy.

\section{ACKNOWLEDGEMENT}

The authors would like to Dr.-Ing. Karsten Jacobsen for the software IMQUAL16 which is used for noise and SNR estimation.

\section{REFERENCES}

Çınar, E., 2014. GÖKTÜRK-2 Uydu Sisteminin Operasyonel Kabiliyetleri, Yer Gözlem Uydu Teknolojileri ve Veri Klymetlendirme Çalıştayl, Ankara. 
Erdogan, M., Yilmaz, A., Eker, O., 2016. The georeferencing of RASAT satellite imagery and some practical approaches to increase the georeferencing accuracy. Geocarto International 31, 647-660.

Küpçü, T., Teke, M., Çabuk, A., 2014. RASAT ve GÖKTÜRK2 Görüntülerinin Ortorektifikasyon Başarımına Referans ve Sayısal Yükseklik Modeli Seçiminin Etkisi, in: Maktav, D., Kılıç, F. (Eds.), 5. Uzaktan Algılama ve Coğrafi Bilgi Sistemleri Sempozyumu, İstanbul (Turkey).
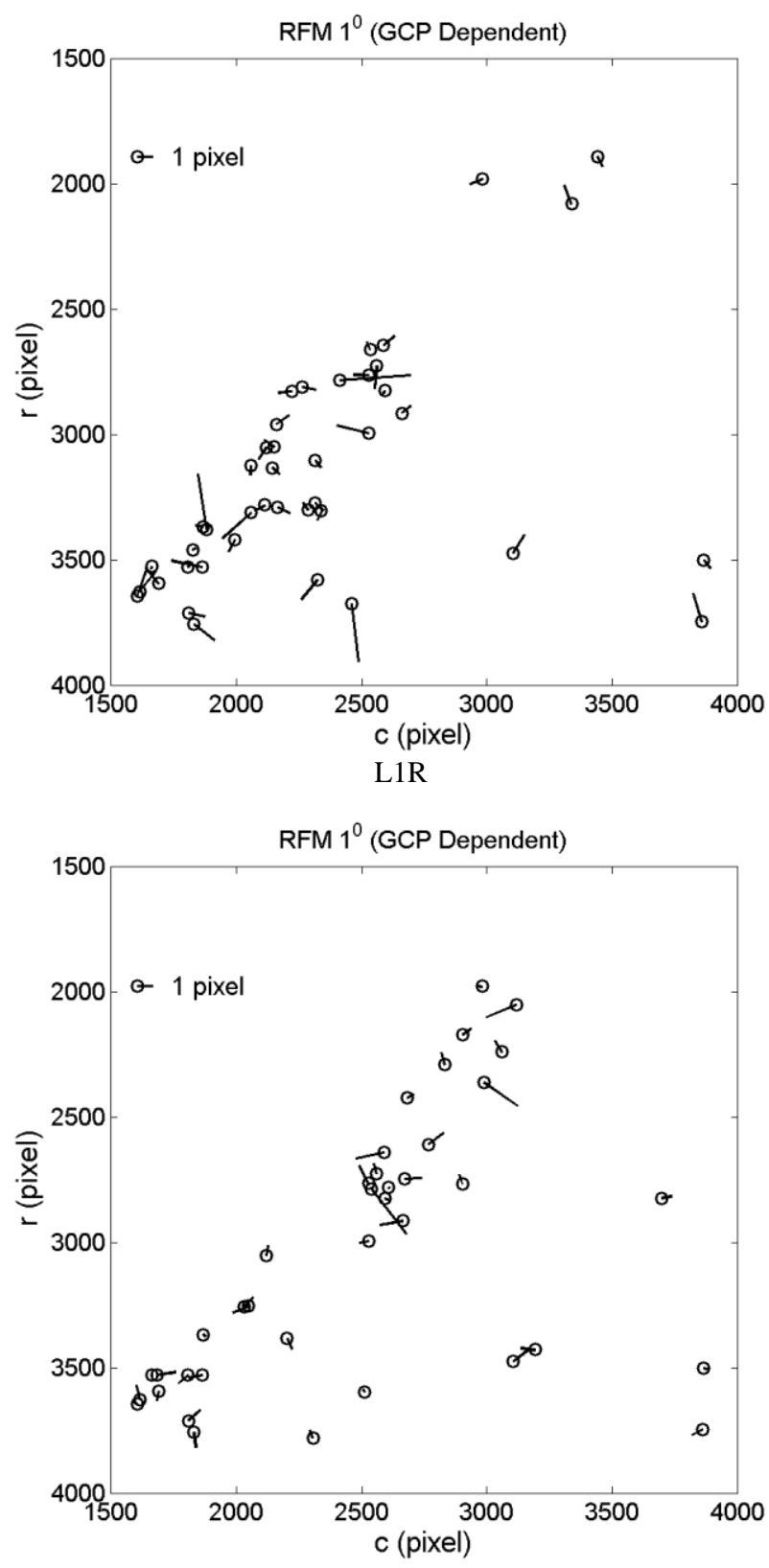

L2
Teke, M., 2016. Satellite Image Processing Workflow for Rasat and Göktürk-2. Havacılık ve Uzay Teknolojileri Dergisi 9, 1-13.

Topan, H., Kutoglu, H.S., 2009. Georeferencing Accuracy Assessment of High-Resolution Satellite Images Using Figure Condition Method. IEEE Transactions on Geoscience and Remote Sensing 47, 1256-1261.

Turkmenoglu, M., Yaglioglu, B., 2013. On-orbit modulation transfer function estimation For RASAT, 6th International Conference on Recent Advances in Space Technologies (RAST) 2013, pp. 181-183.
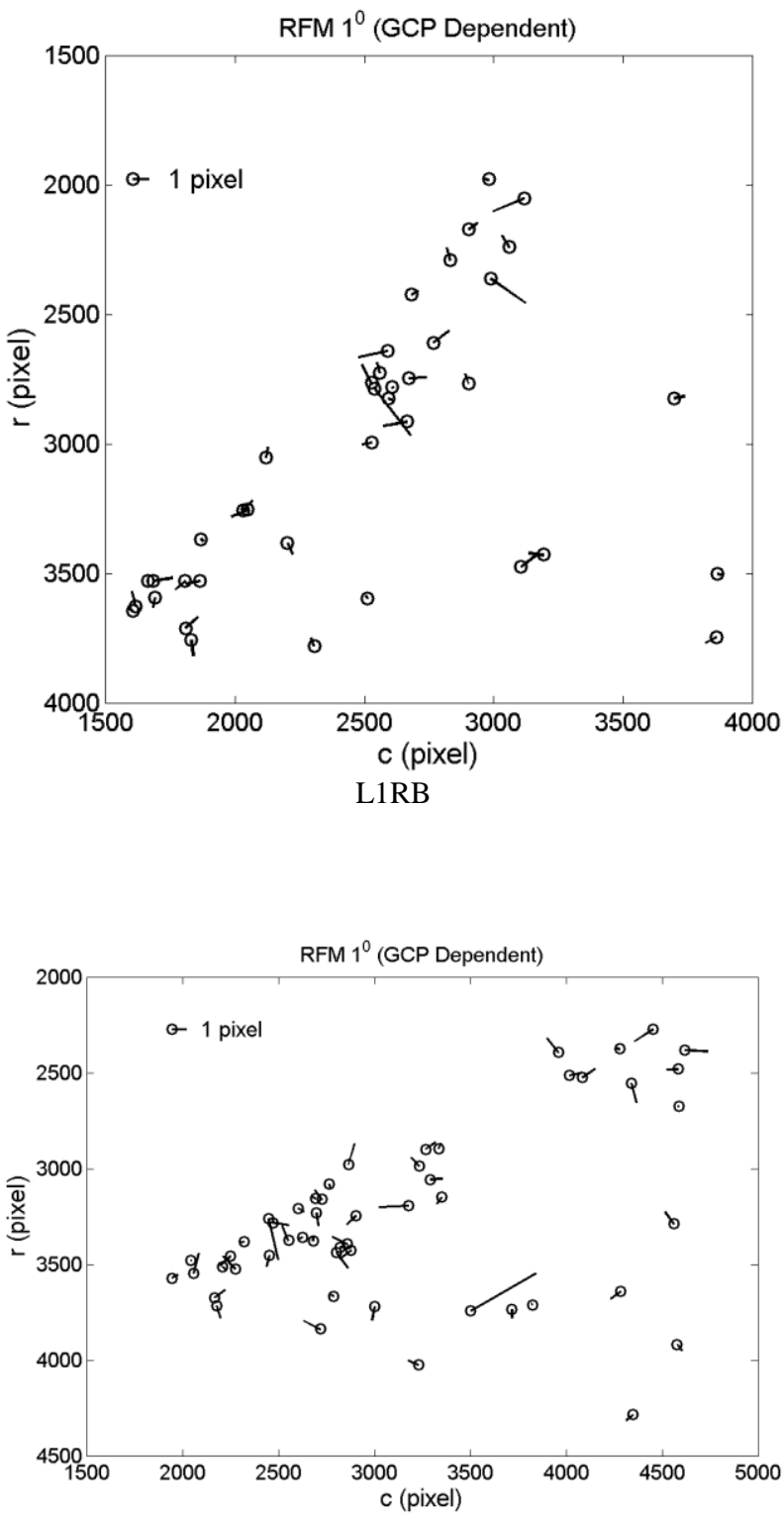

Figure 5. Error vectors derived by 1st order RFM for all levels. 